DOI: https://doi.org/10.47405/mjssh.v6i12.1195

\begin{tabular}{|c|c|}
\hline 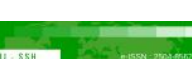 & Malaysian Journal of Social Sciences and Humanities (MJSSH) \\
\hline Malaysian Journal of & Volume 6, Issue 12, December 2021 \\
\hline (MJ. SSH) & e-ISSN : 2504-8562 \\
\hline & $\begin{array}{l}\text { Journal home page: } \\
\text { www.msocialsciences.com }\end{array}$ \\
\hline
\end{tabular}

\title{
Language, Social Networks, and the City
}

\author{
Miriam Devaprasana Samuel' ${ }^{1}$, Rita Abdul Rahman Ramakrishna ${ }^{1}$ \\ ${ }^{1}$ English Language Studies Section, School of Humanities, Universiti Sains Malaysia (USM), Malaysia \\ Correspondence: Miriam Devaprasana Samuel (md_samuel@outlook.com)
}

\begin{abstract}
Research in Malaysian sociolinguistics has seen much development pertaining to its concerns over language in its multilingual, multiracial, post-colonial community. The majority of existing literature however tends to lean towards traditional ideologies to explicate the language situation and linguistic patterns taking place within society. As influential as they are, there is a growing need for research to extend and move beyond traditional parameters so as to better explicate the roles and values of language in the increasingly mobile, transnational, diverse communities found in the city. This is certainly true in the historical city of George Town, Penang where exists an eclectic mix of heritage and urbanity - a contest for fluid and fixed notions of identity, culture, traditions, and language. One approach which has been used to contribute towards the study of linguistic patterns is Social Network Analysis. A notable application of analysis network structures is attributed to Milroy (1987), where the following has emerged: close-knit and dense networks are resistant to outside influences whereas loose-knit, weaker network links are embracing of change. This paper therefore aims to explain Social Network Analysis as a framework and method, how it has been applied in previous studies, and the potential it holds to analyse language in contemporary, urban communities as is found in cities like George Town, Penang.
\end{abstract}

Keywords: George Town, Penang; language maintenance; language shift; social network; urbanity

\section{Introduction}

Sociolinguistics in local contexts have seen much development in its concerns over society and language. In recent years, researchers and analysts have sought to further challenge and extend traditional language ideologies to that which better explicate the relationship between language, society, and urbanity. The approach in such studies offer perspectives and directions towards the study of language and society within the life of the city, and advocates for paradigm shifts to negotiate, challenge, and contribute to existing knowledge (Eckert, 2012; Smakman \& Heinrich, 2017). This is certainly true and necessary within the context of George Town where its history, heritage and demands for urbanisation has produced contested space for a growing, diverse population.

Under the leadership of Francis Light, Penang island and its peninsula counterpart Seberang Perai (previously Province Wellesley) came under the rule and jurisdiction of the British East India Company (the former in 1786, the latter in 1800). Established as the first British settlement in Malaya (and in Southeast Asia), George Town was transformed into the capital city of Penang and as the British administrative centre (Gin, 2015; Zhao et al., 2019). Due to its ideal location, George Town was also developed into a free trade port which appealed to merchants and traders from around the world 
DOI: https://doi.org/10.47405/mjssh.v6i12.1195

with a myriad of riches and goods from the East being imported, and exported to the West, and vice versa. This produced a population that was initially transient in nature, however having seen the potential and development of George Town into a cosmopolitan port-city, more sojourners became settlers who formed communities in shared spaces along ethnic lines throughout the city (Gin, 2015).

By 1957, George Town had seen much social growth with a population of approximately 340,000 (Snider, 1968) however Penang experienced a downturn economically and would only go through forms of recovery in the 1970s through industrial endeavours. In the 1990s, Penang's history and heritage became a commodity lending to an increase in the tourism industry and migration which continued to give rise to its diverse society.

In recognition of its history and heritage, George Town was inscribed into the UNESCO World Heritage List in 2008, which not only elevated its status to both the national and international arena but also encouraged an added dimension in tourism and population - a simple walk around the city centre shows just how much it thrives on its diversity in tourism and population. Whilst the enforcement for better management of its intangible and tangible heritage were put in place, the demands of globalisation needed space for development, and the pursuit of the contemporary, modern, and urban features to make the city even more appealing left the old-trading town at a risk of losing its heritage (Goh, 2014).

In the past decade, rapid urbanisation has taken place along the peripheries of the inner city which is protected by the Core and Buffer Zones (Zhao et al., 2019) and along with economic successes, and the rise of mobility and migration, Penang is now home to a superdiverse, transnational community with society living in constant contact with different cultures, languages, and practices - a push-and-pull between fixities, fluidity, and flexibility.

Whilst existing research provides a foundation towards understanding the language situation in George Town, there is a need for current, if not renewed forms of understanding to examine and explain language use in George Town's contemporary, urban social landscape. This has the added potential to extend traditional language ideology and create more awareness towards the language situation of everyday life in the city.

\section{Languaging in Penang}

Penang's current population stands at 1.77 million with the Bumiputera community at $44.4 \%$, Chinese (39.0\%), Indians (9.4\%), Others (0.3\%) and non-Malaysian citizens at 6.8\% (Department of Statistics Malaysia, 2021). The most recent publication by the Penang Institute estimates that $45 \%$ of Penang's population resides in the Timur Laut and Barat Daya districts of the island with the Chinese ethnic majority in the Timur Laut district and Bumiputera majority in the Barat Daya district (Penang Institute, 2018). These numbers are reflective not only of ethnic group distributions, but also of languages present within the community.

Although the purpose of the current study is not to provide numerical information on languages spoken, it is helpful to be aware of the languages being used in the community. These include community heritage languages such as Hokkien, Hakka, Cantonese, Tamil, Telugu, and Bahasa Tanjong, indigenous minority languages, for example of those from parts of East Malaysia, migrant community languages e.g. Indonesian, Nepali, Bengali, and immigrant community languages e.g. German, Korean, Japanese. These are present alongside other dominant languages available such as Mandarin, English and Standard Malay (the National Language). As a result, an immersive experience of the city includes being surrounded by this soundscape where every individual plays a part in the processes of languaging in Penang.

Existing literature has shown the importance of language analysis in Penang and has provided knowledge towards understanding the value and roles of languages within the community. These include studies on linguistic landscape (e.g. Said \& Ong, 2019; Ong, 2020a), language shift (e.g. 
Wang, 2016), language maintenance (e.g. Ong, 2018), language management (e.g. Wang, 2017) and language vitality (e.g. Ting \& Teng, 2021). The majority of research however is centred on language shift, and language maintenance among particular ethnolinguistic communities.

Ramachandran et al. (2019) for example add to language studies among minority groups in Malaysia by examining language choice within the Penang Eurasian community. By utilising the domain concept, the researchers were able to investigate the respondents' preferred language and factors which influenced their choice. This made it possible to identify whether language shift was occurring, and to what extent. Their findings not only showed a preference for English in all domains but that it had also become the more dominant language used instead of the individuals' heritage language. The main factor contributing towards this were perceptions and attitudes towards the role and value of English i.e. economic power, social status. The study is significant as it explicates a shift in language use and choice within the Penang Eurasian community and predicts that this shift may occur at a faster rate when compared to Eurasians in other parts of Malaysia due to the lack of spatial concentration. It is also helpful in providing an avenue for comparison with other Eurasian communities around Malaysia, as well as in raising awareness towards the status of the various heritage language(s) and cultures and the implications of language shift on these aspects.

Other ethnolinguistic groups at the core of language studies are within the Penang Chinese community, namely the Hokkien and Hakka speaking groups. Wang's (2016) research, for example, examined language use of a Chinese Catholic community in Balik Pulau which revealed that whilst the senior church members maintained the use of the Hakka language for church services, the same cannot be said for the younger generation who preferred either Mandarin or English for variables including communication, networking, and convenience. Ong (2020b) extends the study of language maintenance among the Hakka community by explaining that while there are efforts of language maintenance through their use at home, with friends and at work, this was true of the older generation who were determined to continue these practices in order to retain forms of ancestry, identity, and culture.

Similar notions are evident with Penang Hokkien which has also garnered much attention from the public and NGOs who advocate for the maintenance of Hokkien in attempts to resist the patterns of change that are taking place. Ong and Said's (2021) study which focuses on the older generation of Penang Hokkien users evidence that the language is being maintained. Despite encouraging results, they propose the need for more rigorous and dynamic measures in order to maintain these languages to decelerate the shifts in language choice which are occurring within the various ethnic-Chinese groups on Penang island.

The examples above exhibit similar concluding strands in research i.e. evidence of language shift within ethnolinguistic groups. These patterns help researchers and analysts make sense of the language contact in Penang and provide evidence towards language shift by identifying factors which influence language choice, preference for language use in selected domains and measures to maintain the use of community heritage language(s). However, research should be further extended to the study of language in relation to the city and urbanity, either among ethnolinguistic groups or regardless of ethnicity and their assumed mother tongues (i.e. Indians $=$ Tamil; Chinese $=$ Hokkien). Approaches like these offer perspectives on the language situation within a superdiverse, transnational society and has the potential to expand our understanding of the mechanisms behind the language situation in the city which can further contribute towards developing better policies to support the various language users and their needs in contemporary society.

\section{Networks as Social Structures for Language Analysis}

Networks are considered as mobile and flexible structures made up of variables (nodes) which represent the various ways individuals and groups interact, move around, circulate, and emerge. The relationship between the nodes is known as edges, of which is analysed. Edges (links) provide information toward the direction and strength of the relationship between the nodes. Positive 
correlations between the nodes represent a positive edge, whereas negative correlations represent a negative edge. The weight (thickness, density) of an edge is also key towards identifying whether an edge is positive or negative i.e. a thicker, denser edge represents a positive edge, conversely for a negative edge. Figure 1 depicts a simple network structure between five nodes (A-E), with the size and colour of the edges representing the different relationships between the nodes (green $=$ positive network; red=negative network). The absent relationship between nodes $\mathrm{A}$ and $\mathrm{B}$ represent an unweighted edge.

Figure 1: A Simple Network Model

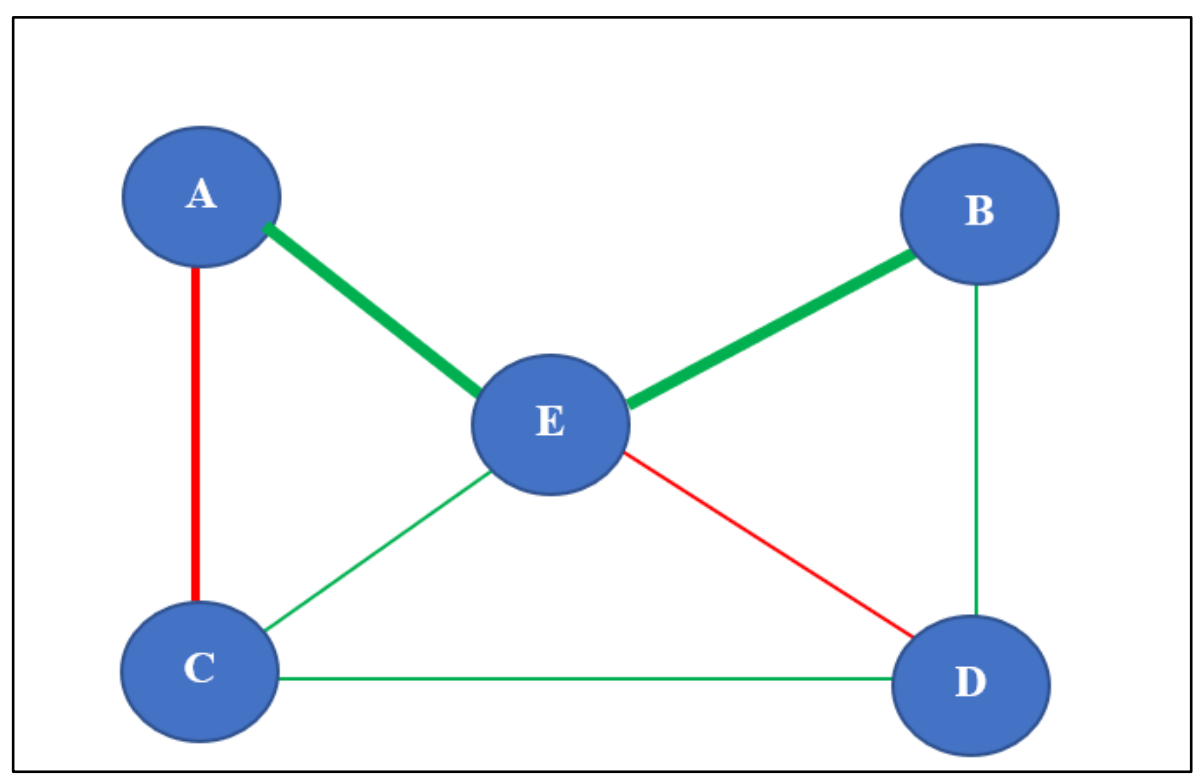

Source: Adapted from Hevey (2018)

To emphasise, network analysis has been applied in various fields of research. In Sociology, the concept of social networks (though not to be confused with its popular use to refer to social media) has extended from face-to-face interactions to digital and online scapes (Scott, 2017). To systematically examine and interpret these relationships, Social Network Analysis (SNA) was introduced to investigate the complex relationships between individuals, the larger social networks of which the individual is a part of, and the members' social behaviour (for example, language use). It can therefore be applied either as an analytical tool, or an explanatory device to equip researchers in understanding the complex nature of networks and social behaviour (Meyerhoff, 2006). In brief, network analysis provides an approach to analyse social structures which emerge through, and from relations among, and between individuals. It has been utilized both as a framework and/or method and has been applied in various fields of research including public health, management, and linguistics.

\section{Social Network Analysis (SNA) in Language Studies}

Within the field of Sociolinguistics, SNA is used as a foundation to address questions which revolve around language practices within particular communities. These include the following:

i. How do the connections we have with one another affect the language(s) we use?

ii. What is the effect of our language practices on the building of our social relations (which can be further extended to notions of 'identity' and 'belonging')?

iii. Are there any relations between language use and our view on its users, and if so, what are their effects on social relationships? 
To examine these questions, the analyst focuses on the strengths of the network relations, the roles of its members, patterns which emerge, and flow among and between the network to describe and infer the relationship between social entities and the implications towards social behaviours.

SNA has generally been explicated through quantitative measures and by providing visual representations of the network. However, Scott (2017) argues that while mathematical and quantitative approaches may be used to statistically describe these relations, network analysis is highly dependent on qualitative measures to examine and infer the structure and development of a network. Hence, two approaches have been developed to help researchers use SNA as an analytical tool 1) the wholenetwork approach, and 2) the egocentric network (see Wei, 2019, for further detail). Both approaches are used to measure relationships between individuals, with the former examining the overall structure of the network and the latter focusing on the size and content which emerge between the ties within a personal network.

Social networks have extensively been used in language research, with particular focus in variationist sociolinguistics. Gumperz (1958), for example, applied SNA as a framework to describe whether speech communities were 'close-knit' or 'open-knit'. Labov (1973) used SNA as an analytical component where data collected was used to describe and infer variations and changes to language use and practice. More recent whole-network approach studies have contributed towards explicating the relationship between social networks and linguistic skills such as Lev-Ari (2015) who focused on the aspect of network size and semantic skills, with the general understanding that variations on semantic skills are more likely to be found within larger social network structures. By conducting two studies, she not only found confirmation to her theory, but further extends this knowledge by explaining that a higher number of sources in social network structures encourages a greater ability in the use and interpretation of terms and their meanings. A 2017 study by Tribur sought to discover the relationship between social networks and linguistic diversity among Amdo Tibetan (AT) speakers. By using the labels endoteric and exoteric to categorise the community's speech varieties, she argues that the small, multiplex, and dense social network structures among endoteric AT speech communities result in less innovative patterns of change and are linguistically homogeneous, as opposed to exoteric AT communities whose networks are described as large, loose, and uniplex, and are linguistically heterogenous.

The second approach - the egocentric network, focuses on the individual and their ties within the network. A crucial perspective which has emerged is that an individual performs daily tasks through the different strengths and types of their interpersonal ties within their personal communities (Mitchell, 1986 as cited in Milroy and Llamas, 2013). Perhaps the most notable use of the egocentric social network as an analytical tool is Milroy's (1987) Belfast study, whose investigation detailed the relationship between language patterns and the personal network structure of individuals within an urban speech community in Belfast. Through the study, the Network Strength Scale was developed to assist researchers in better analysing the different characteristics evident within each network (with regards to the speakers' relations within the neighbourhood, with kin, and friends. With a maximum score of 5 , speakers received a point if they fell under the following categories:

- were members of a high-density, territorially based group (e.g., a bingo or card-playing group, a gang or a football team, or football supporters' club)

- had kinship ties with more than two households in the neighbourhood

- worked in the same place as at least two others from the neighbourhood

- worked in the same place as at least two others of the same sex from the neighbourhood

- associated voluntarily with workmates in leisure hours

(Milroy and Gordon, 2003, p. 121)

The analyses revealed a fundamental pattern - speakers whose ties with the neighbourhood were strongest were found to be those considered as strong vernacular speakers (keeping in mind that these results involved aspects such as age and gender). 
Other studies which have both applied the concept of network structures and developed the use of indicators of local practices include Edwards (1992) who used the Vernacular Culture Index as the indicator for the individuals' level of participation and integration within the African American neighbourhood community(s). Lippi-Green's (1989) study on social network structure and language variation among the inhabitants of a village in the Austrian Alps detailed the difficulties of applying concepts like social class to determine linguistic patterns within the community, and therefore developed a scale with 16 indicators including those within the domains of friendship, family (kin), and work, as well as those which were specific to the local context.

From the various studies conducted, rises a general pattern between variables which affect the individual and their relations with members of the network. As explicated by Milroy and Llamas (2013),

"If a network consists chiefly of strong ties, and those ties are multiplex or manystranded, and if the network is also relatively dense - that is, many of ego's ties are lined to each other - then such a network has the capacity to support its members in both practical and symbolic ways" (p. 410).

This is to say that speakers would be less susceptible to external changes when their personal network structures have multi-stranded, strong and/or dense ties as opposed to those whose ties are weak in nature, which encourages shifts and change in linguistic behaviours.

Whilst a majority of network and language analysis has been applied in predominantly monolingual speech communities, research on analysing network structures and their implications on linguistic patterns has emerged within bilingual and immigrant settings. Some of the earlier works in bilingual communities include Gumperz (1982) who accounts that due to processes of urbanisation, shifts in the local economy, and improvements with transportation and communication, the once close-knit unit traditionally found within the Slovenian-Germany farming community were less dependent on one another for moral support, thus a diminishing strength within the local network structure. This led to a shift not only in social and communicative practices, but also in language use from Slovenian to German.

Li Wei (1994) conducted his study of language shift and language choice among Chinese families of three generations who were living in the UK. To better reflect the community, he analysed these linguistic patterns by using ethnicity and peer-groups as an index in three different networks: exchange, interactive and passive. He argues that the ethnicity of the members in the individual's social network best predicted their language choice and use, especially so in relation with the exchange network (where the individual and members of the network build their relationship on exchanges like aid, support, advice, besides routine and frequent interactions). Though the index worked at a lesser degree within the interactive network (where though there may be frequent and routine interaction with members of the network, there is a lower possibility that this involves exchanges), the peer-group index revealed that a greater number of Chinese peers influenced language maintenance and use. For example, parents who had a greater contact with peers of their parent's generation were more likely to use Chinese whereas parents were labelled as increasingly bilingual if they had more contact with peers from their children's generation.

Matsumoto and Britain (2009) further extend the use of social network as a framework to understand the mechanisms behind change in linguistic patterns in The Republic of Palau - a postcolonial country with a multilingual community. By doing this, they also contribute to research and the application of social network structures in rural, immigrant communities. Using Li Wei's (1994) study as a foundation, they adopted the use of the exchange, interactive and passive networks as well as the ethnic index to mirror the relationship between the individual and the degree of their associations (or lack of) with the previous colonial rule (here the researchers only used the Japanese ethnic index). Their study highlights several important aspects to the use of social network in multilingual post-colonial communities: 1) a greater degree of attachment or association with the former colonial power results in a greater level of colonial language maintenance (Japanese); 2) the strong ties between Japanese- 
oriented network members reinforced the maintenance of Japanese and the capacity to withstand other influences. Conversely, weaker ties enabled the spread and use of English and 3) that the correlation for Japanese language maintenance was dependent on families which identified themselves as Japanese-Palauan.

Though having been applied in different contexts of communities (i.e. bilingual, immigrant, rural, postcolonial), the examples above explicate the same fundamental principle - networks with strong ties are able to resist the pressures of social change, and support the continued use of minority languages, whereas networks with weaker ties encourage language shift within the community. Their results correlate with patterns which are evident in language research in monolingual communities. Of significant consideration is that the literature on social network ties and linguistic patterns have largely been applied to close-knit communities where it may be easier to identify the strength and density within personal network structures. This poses a challenge especially within loose-knit communities where the various socio-economic differences may prove difficult for meaningful comparison, as well as with communities whose network structures may not be as dense or multistranded as is the case for mobile speakers, hence the theory that communities with weak network structures are more susceptible to external changes.

Another problem to consider is that the majority of SNA in language studies has been Western-centric. As much as they have contributed understanding towards language variation and language change, there is a need to provide perspectives towards utilizing these concepts in South-East Asian, multilingual, urban populations as is the case of George Town, Penang, and wider Malaysia. What is unique, and certainly different of Malaysia to its Western counterparts is that its population consists of the major ethnic groups i.e. the indigenous (Bumiputera) community, the minority ethnic Chinese, Indians, and Others, the immigrant communities, migrants, expatriates, and refugees resulting in a society where 'diversity' merely describes the tip of the iceberg. Both Malaysians and non-Malaysians of different cultures, identities, languages, traditions, and practices are brought together within shared spaces.

Therefore, individuals who belong to, or retain close ties with their ethnolinguistic communities may do so through a myriad of aspects independent of language use and choice. Omar (1991), as cited in David (1998) supports this by suggesting that within the Malaysian context, the role and value of language is not as instrumental in retaining ethnic identity and heritage as much as it is necessary for the continued exposure with those of the same ethnicity. In other words, for as long as the individual retain links and ties with members of the same ethnic group within their personal network structure, they will be able to maintain their ethnic identity and heritage. This leads to growing appeals for researchers to question just how far Western-constructs in research can truly bring justice for a better understanding of the language situation in Malaysia.

While Milroy's (1987) study advocates for the notion that a close-knit, dense network is instrumental in language maintenance, there are a number of researchers whose studies conducted within the Malaysian context argue that research utilizing Western-centric models and frameworks have resulted in conflicting outcomes. With a focus on minority ethnolinguistic communities, they offer perspectives on the universality of these constructs for research on SNA in language studies within the Malaysian context. Some of the works contributing to the literature include David (1998, 1999), David and Faridah (1999), Joan and Ting (2017), and Alagappar et al., (2018).

David's (1999) study on the Sindhi community in Malaysia exhibited language shift despite its community being one with a dense and close-knit network. Her study showed that regardless of their migratory patterns and settlement in Malaysia, close familial relationships within members, with frequent and routine forms of interaction and communication, the Sindhi community showed a greater preference for the more dominant languages i.e. English and Malay (the National language) than their ethnic language. A similar strand of understanding was reflected in David and Faridah's (1999) study which highlighted the shifts in linguistic patterns among the Eurasian Portuguese community in Malacca. Based on Chan (1969) who argued that the close-knit neighbourhood within the Settlement was reason for the community's preference for their ethnic language (as cited in David and 
Faridah,1999), they found that thirty years later and despite living within the same spatial concentration, there has been a shift in preference for language use within the community.

Seeing the need to further understand the differences in outcome, Govindasamy and Nambiar (2003) concentrated on another immigrant minority community - the Malayalees in Malaysia, their social network structures, and its implications on language shift/maintenance. The researchers analysed portions from the collected data on the following: the respondent's language use within the family or home, and friend domain, their language proficiency, and age (with the older respondents comprising the first generation of settlers in Malaysia from Kerala). Their results showed that even though there is a sense of closeness within the Malayalee community (specifically within friendship groups), the community is gradually becoming a low-density network as age decreases. They further extend this notion by explaining the decreasing value in kinship ties as children find themselves moving out of the community into spaces of work, living and marriage which embraces the diversity of multiracial Malaysia. Govindasamy and Nambiar (2003) show that although they may still fall under the category of being a close and dense network, there is lesser reliance and alliance among members of the community. This, along with the decline of language proficiency in Malayalam among the younger generation who were found to be more fluent in Malay, and the preference for English as the medium of interaction among family and friends regardless of ethnicity, Govindasamy and Nambiar (2003) conclude that the linguistic patterns of the Malayalee community in Malaysia was headed towards a language shift, showing a parallel with David (1999) and David and Faridah (1999).

Adding to the literature is Mukherjee (2003) who examined the role of women on linguistic patterns within the close-knit Bengali community in Malaysia. She uses perspectives from Milroy's (1987) network analysis concept and that of Le Page and Tabouret Keller (1985) who assert the individual's value, and role on their personal network structure on language choice (as opposed to group(s) determining the individual's linguistic behaviour). By analysing data through ethnolinguistic methods, Mukherjee (2003) supports the notion for fluidity in language choice and is largely dependent on how the individual chooses to identify themselves. Furthermore, she found that there was a strong sense of ethnic identity among the participants who asserted the need for language maintenance within the community, however the notions of language and power come into play especially within the younger Bengali women who see the economic power English possesses (which also gives way to their preference for English over Malay).

More recently, Joan and Ting (2017) conducted a study among thirty teenagers who had moved to Bintulu from Kejaman (a minority indigenous group living in the interiors of Belaga, Sarawak). The aims of the study were to investigate the participant's skills in speaking Kejaman and the role of the participant's social network structures in relation to their language use and choice. Their study showed that the female participants had better oral proficiency than the male participants, with similar results found in Milroy (1987) and Li Wei (1994). The majority of the participants also rated themselves as 'good' speakers of Kejaman with one who rated themselves as having a weak proficiency in the language. In terms of density and multiplexity, Joan and Ting (2017) found that the participant's social networks were close-knit, with the majority of them having contacts who knew one another.

Following Li Wei's (1994) use of exchange and interactive networks, the study also described a higher density with the exchange network compared to the interactive network and concluded that the participant's relationship with kin had a higher role and value, followed by contacts in school, and finally with their neighbours. When comparing their results to previous studies such as Milroy (1987) and Li Wei (1994) who suggest the multiplexity of role relationships for networks which are dense, and that networks in rural settings would normally be dense and multiplex when compared to urban counterparts (Milroy and Margrain, 1980 as cited in Joan and Ting, 2017), the current study found conflicting results - though the networks in the current study were found to be dense, it did not equate to multiplexity in role relationships. Therefore they argue that the level of knowing each member of the network may not necessarily support the use and choice of community language(s). The study also explicates on the use of Kejaman in relation to other languages and found that within the exchange network, there is evidence for both language shift and language maintenance, however a very low use of Kejaman in the interactive network, indicating the possibility of ethnic diversity in the participant's 
interactive network for which would require the use of other languages. Joan and Ting (2017) conclude that while there the Kejaman participants may have dense, close-knit networks, their language behaviours are not dependent on their social networks, and instead suggest that future research should utilise the ethnic index when analysing networks and language behaviour to better understand language use and choice in speech communities.

The studies expounded above provide insight towards taking a cautionary approach when applying Milroy's (1987) theory of network structure and language behaviour. Although it provides an ideal, it cannot be normalised in language research across communities, especially those in Malaysia where its people are both exposed to and have embraced the use of different languages for different settings, perhaps even a play on identities according to the different groups they may be a part of (David, 1999). Hence, the need for more localised and contextualised frameworks and models of research which better fit the study of local communities, their network structures, and its relationship with linguistic patterns and language behaviour(s).

\section{Conclusion}

Based on existing literature on both the application of network analysis and language studies in Penang (and wider Malaysia) rises the need for alternative, collaborative strategies to challenge and expand on the knowledge of language use in urban George Town. This also includes broadening our understanding of ethnicity, ethnic identity, and heritage by taking to account the need of extending studies beyond ethnolinguistic parameters to those which include the influence of other ethnicities on an individual's language behaviour (if any). Considering the superdiverse, transnational society in the city, network analysis provides an avenue for researchers and analysts to examine how the complex social networks of an urban, multilingual, and multicultural population influences the flexibility of social behaviour and attitudes, thereby contributing to the understanding of language use in contemporary George Town. Engaging in such research may also contribute towards expanding our discourse on traditional approaches to notions of identity, culture, and tradition especially in a nation which celebrates its unity through diversity.

\section{Acknowledgment}

Acknowledgement to the Ministry of Higher Education Malaysia for the Fundamental Research Grant Scheme with the Project Code: FRGS/1/2019/SSI01/USM/02/2.

\section{References}

Alagappar, P. N., Dealwis, C., \& David, M. K. (2018). The Influence of Age Cohorts and Social Networks on the Language Choices of the Non-Indigenous Tamil Minority in Kuching, Sarawak, Malaysia. Kemanusiaan the Asian Journal of Humanities, 25(1), 69-93. https://doi.org/10.21315/kajh2018.25.1.4

David, M. K. (1998). Language shift, cultural maintenance, and ethnic identity; a study of a minority community: the Sindhis of Malaysia. International Journal of the Sociology of Language, 130(1), 67-76. https://doi.org/10.1515/ijsl.1998.130.67

David, M. K. (1999). Language shift Amongst The Sindhis of Malaysia. South Pacific Journal of Psychology, 10(1), 61-67. https://doi.org/10.1017/s0257543400001012

David, M. K., \& Faridah, N. (1999). Language Maintenance or Language Shift in the Portuguese Settlement of Malacca in Malaysia. Migracijske $i$ Etničke Teme, 15(4), 465-481. https://hrcak.srce.hr/109484

Department of Statistics, Malaysia. (2021). Population Quick Info. Department of Statistics Malaysia Official Portal. http://pqi.stats.gov.my/result.php?token=8b523b13c27c456cd4b2600fdd5fc0cb 
DOI: https://doi.org/10.47405/mjssh.v6i12.1195

Eckert, P. (2012). Three Waves of Variation Study: The Emergence of Meaning in the Study of Sociolinguistic Variation. Annual Review of Anthropology, 41(1), 87-100. https://doi.org/10.1146/annurev-anthro-092611-145828

Edwards, W. F. (1992). Sociolinguistic Behavior in a Detroit Inner-City Black Neighborhood. Language in Society, 21(1), 93-115. https://doi.org/10.1017/S0047404500015050

Gin, O. K. (2015). Disparate Identities: Penang From A Historical Perspective, 1780-1941. Kajian Malaysia, 33(2), 27-52. http://web.usm.my/km/33(Supp.2)2015/km33s22015_03.pdf

Goh, D. P. (2014). Between History and Heritage: Post-Colonialism, Globalisation, and the Remaking of Malacca, Penang, and Singapore. TRaNS: Trans-Regional and-National Studies of Southeast Asia, 2(1), 79-101. https://doi.org/10.1017/trn.2013.17

Govindasamy, S., \& Nambiar, M. (2003). Social networks: applicability to minority communities in multilingual settings. International Journal of the Sociology of Language, 2003(161), 25-45. https://doi.org/10.1515/ijs1.2003.027

Gumperz, J. J. (1958). Dialect Differences and Social Stratification in a North Indian Village. American Anthropologist, 60(4), 668-682. https://doi.org/10.1525/aa.1958.60.4.02a00050

Gumperz, J. J. (1982). Language and social Identity. Cambridge University Press.

Hevey, D. (2018). Network analysis: a brief overview and tutorial. Health Psychology and Behavioral Medicine, 6(1), 301-328. https://doi.org/10.1080/21642850.2018.1521283

Joan, A., \& Ting, S. H. (2017). Influence of Social Network on Language Use of Kejaman Speakers in Sarawak, Malaysia. Oceanic Linguistics, 56(1), 22-41. https://doi.org/10.1353/ol.2017.0001

Labov, W. (1973). Sociolinguistic Patterns (1st ed.). University of Pennsylvania Press.

Lev-Ari, S. (2015). How the Size of Our Social Network Influences Our Semantic Skills. Cognitive Science, 40(8), 2050-2064. https://doi.org/10.1111/cogs.12317

Lippi-Green, R. L. (1989). Social network integration and language change in progress in a rural alpine village. Language in Society, 18(2), 213-234. https://doi.org/10.1017/s0047404500013476

Matsumoto, K., \& Britain, D. (2009). The role of social networks in understanding language maintenance and shift in post-colonial multilingual communities - The case of the Republic of Palau in the Western Pacific. Essex Research Reports in Linguistics, 58(2). http://repository.essex.ac.uk/92/1/errl58-2.pdf

Meyerhoff, M. (2006). Introducing Sociolinguistics (1st ed.) [E-book]. Routledge. https://doi.org/10.4324/9780203966709

Milroy, L. (1987). Language and social networks (2nd ed.). Blackwell.

Milroy, L., \& Gordon, M. (2003). Social Relationships and Social Practices. In Sociolinguistics: Method and Interpretation (pp. 116-135). Blackwell Publishers. https://doi.org/10.1002/9780470758359

Milroy, L., \& Llamas, C. (2013). Social Networks [E-book]. In The Handbook of Language Variation and Change (2nd ed., pp. 407-427). John Wiley \& Sons, Inc. https://doi.org/10.1002/9781118335598.ch19

Mukherjee, D. (2003). Role of women in language maintenance and language shift: focus on the Bengali community in Malaysia. International Journal of the Sociology of Language, 2003(161), 103-120. https://doi.org/10.1515/ijsl.2003.023

Ong, T. (2018). Language Maintenance in Malaysia: A Case Study of the Chinese Community in Penang [Doctoral Thesis, Griffith University, Australia]. Griffith Research Online. https://doi.org/10.25904/1912/1180

Ong, T. (2020a). Cast in Iron: Remembering the Past in Penang. In Multilingual Memories: Monuments, Museums and the Linguistic Landscape (pp. 213-236). Bloomsbury Academic. https://doi.org/10.5040/9781350071285.ch-010

Ong, T. (2020b). Contemporary Hakka Language Maintenance in Multilingual Penang, Malaysia. Revista Linguagem \& Ensino, 23(4), 1349-1369. https://doi.org/10.15210/rle.v23i4.17267

Ong, T. W. S., \& Said, S. B. (2021). Selective Language Maintenance in Multilingual Malaysia. Indigenous Language Acquisition, Maintenance, and Loss and Current Language Policies, 207-228. https://doi.org/10.4018/978-1-7998-2959-1.ch009

Penang Institute. (2018). Penang: Population and Demographics - Penang Institute. https://penanginstitute.org/resources/key-penang-statistics/visualisations-of-keyindicators/penang-population-and-demographics/ 
Ramachandran, P. A., Ramakrishna, R. A. R., \& Lah, S. C. (2019). Language Choice Of The Eurasian Community In Penang: A Sociolinguistic Study. Future Academy, 626-636. https://doi.org/10.15405/epsbs.2019.09.69

Said, S. B., \& Ong, T. (2019). Tracing Linguistic Changes on Shop Signs in Malaysia: A Diachronic Examination of George Town, Penang. Central European Journal of Social Sciences and Humanities, 33, 209-230. https://doi.org/10.17651/SOCJOLING.33.14

Scott, J. (2017). Social Network Analysis (4th ed.) [E-book]. SAGE Publications Ltd.

Smakman, D., \& Heinrich, P. (2017). Urban Sociolinguistics (1st ed.) [E-book]. Taylor \& Francis. https://doi.org/10.4324/9781315514659

Snider, N. L. (1968). What Happened in Penang? Asian Survey, 8(12), 960-975. https://doi.org/10.2307/2642150

Ting, S. H., \& Teng, J. Z. M. (2021). Chinese teenagers' perceptions of vitality of Hokkien Chinese in Penang, Malaysia. International Journal of the Sociology of Language, $O(0)$. https://doi.org/10.1515/ijsl-2020-0024

Tribur, Z. (2017). Social network structure and language change in Amdo Tibetan. International Journal of the Sociology of Language, 2017(245), 169-206. https://doi.org/10.1515/ijsl-20170007

Wang, X. (2016). Language Maintenance or Language Shift? The Role of Religion in a Hakka Catholic Community in Malaysia. International Multilingual Research Journal, 10(4), 273-288. https://doi.org/10.1080/19313152.2016.1192850

Wang, X. (2017). Family language policy by Hakkas in Balik Pulau, Penang. International Journal of the Sociology of Language, 2017(244), 87-118. https://doi.org/10.1515/ijsl-2016-0058

Wei, L. (1994). Three Generations, Two Languages, One Family: Language Choice and Language Shift in a Chinese Community in Britain. Multilingual Matters.

Wei, L. (2019). Social network analysis. In J. Darquennes, J. Salmons, \& W. Vandenbussche (Eds.), Language Contact: An international handbook (edited volume) (Vol. 1, pp. 561-573). De Gruyter Mouton. https://doi.org/10.1515/9783110435351-046

Zhao, L., Wong, W. B., \& Hanafi, Z. B. (2019). The evolution of George Town's urban morphology in the Straits of Malacca, late 18th century-early 21st century. Frontiers of Architectural Research, 8(4), 513-534. https://doi.org/10.1016/j.foar.2019.09.001 